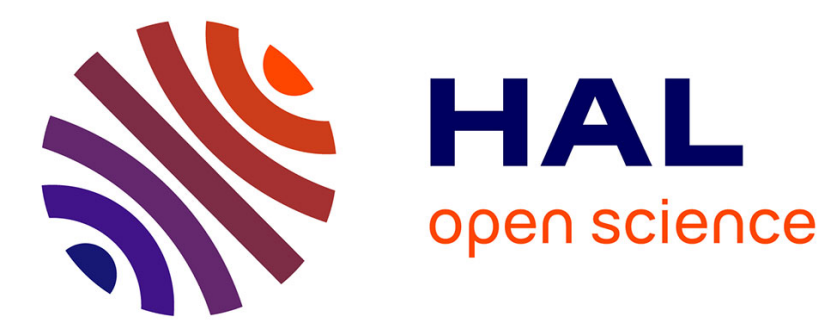

\title{
Self-selection and the Power of Incentive Schemes: An Experimental Study
}

\author{
Jana Vyrastekova, Sander Onderstal, Pierre Koning
}

\section{To cite this version:}

Jana Vyrastekova, Sander Onderstal, Pierre Koning. Self-selection and the Power of Incentive Schemes: An Experimental Study. Applied Economics, 2011, pp.1. 10.1080/00036846.2011.587787 . hal00716630

\section{HAL Id: hal-00716630 \\ https://hal.science/hal-00716630}

Submitted on 11 Jul 2012

HAL is a multi-disciplinary open access archive for the deposit and dissemination of scientific research documents, whether they are published or not. The documents may come from teaching and research institutions in France or abroad, or from public or private research centers.
L'archive ouverte pluridisciplinaire HAL, est destinée au dépôt et à la diffusion de documents scientifiques de niveau recherche, publiés ou non, émanant des établissements d'enseignement et de recherche français ou étrangers, des laboratoires publics ou privés. 


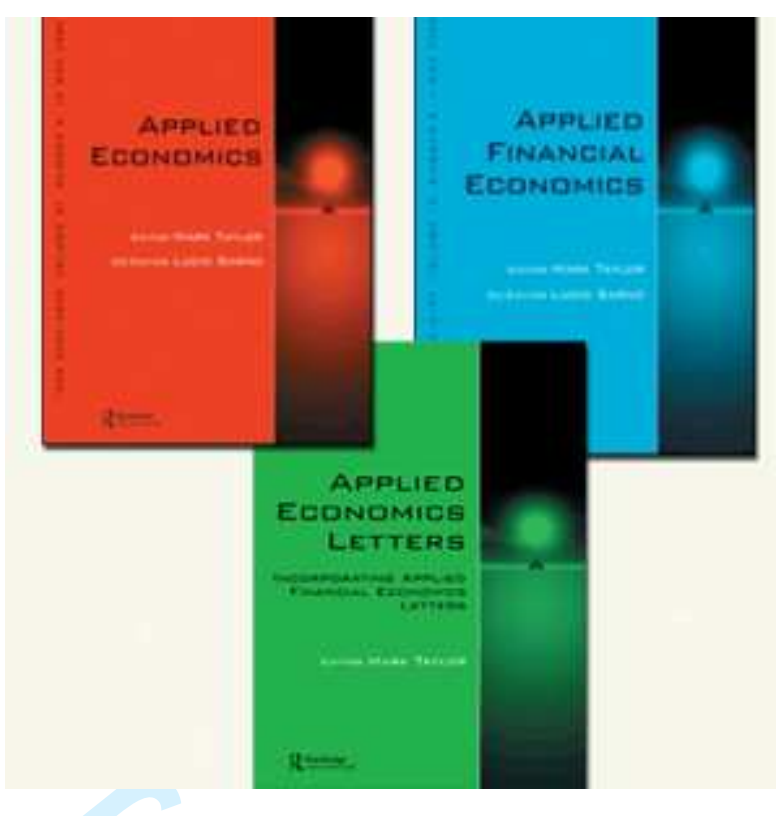

\section{Self-selection and the Power of Incentive Schemes: An Experimental Study}

\begin{tabular}{|r|l|}
\hline Journal: & Applied Economics \\
\hline Manuscript ID: & APE-2010-0358.R1 \\
\hline Journal Selection: & Applied Economics \\
\hline Date Submitted by the \\
Author: & 20-Apr-2011 \\
\hline Complete List of Authors: & $\begin{array}{l}\text { Vyrastekova, Jana; Radboud University Nijmegen, Nijmegen School } \\
\text { of Management } \\
\text { Onderstal, Sander; University of Amsterdam } \\
\text { Koning, Pierre; CPB Netherlands Bureau for Economic Policy } \\
\text { Analysis }\end{array}$ \\
\hline JEL Code: & $\begin{array}{l}\text { C91 - Laboratory, Individual Behavior < C9 - Design of Experiments } \\
\text { < C - Mathematical and Quantitative Methods, J33 - Compensation } \\
\text { Packages|Payment Methods < J3 - Wages, Compensation, and } \\
\text { Labor Costs < J - Labor and Demographic Economics, M52 - } \\
\text { Compensation Methods and Their Effects (stock options, etc.) }<\text { M5 } \\
\text { - Personnel Economics < M - Business Administration and Business } \\
\text { Econ; Marketing; Accounting }\end{array}$ \\
\hline Keywords: & $\begin{array}{l}\text { Incentive scheme, Self-selection, Laboratory experiment, Trust, } \\
\text { Reciprocity }\end{array}$ \\
\hline &
\end{tabular}




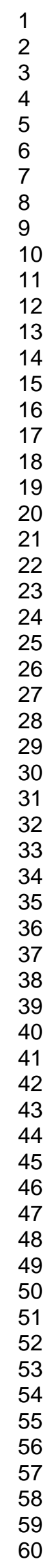

SCHOLARONE ${ }^{m}$
Manuscripts

25

26

27
28

29

30

32

33

34

35

36

37

38

40

41

42

44

45

46

47

48

49

51

52

54

55

57

58

59

60 


\title{
Self-selection and the Power of Incentive Schemes: An Experimental Study*
}

\author{
Jana Vyrastekova, ${ }^{\dagger}$ Sander Onderstal, ${ }^{\ddagger}$ and Pierre Koning ${ }^{\S}$ \\ April 20, 2011
}

\begin{abstract}
We examine how self-selection of workers depends on the power of incentive schemes and how it affects team performance if the power of the incentive schemes is increased. In a laboratory experiment, we let subjects choose between (lowpowered) team incentives and (high-powered) individual incentives. We observe that subjects exhibiting high trust or reciprocity in the trust game are more likely to choose team incentives. When exposed to individual incentives, subjects who chose team incentives perform worse if both the unobservable interdependency between their effort and their incentive to cooperate under team incentives are high.
\end{abstract}

JEL Classification: C91, J33, M52

Key words: Incentive scheme; Self-selection; Laboratory experiment; Trust; Reciprocity

${ }^{*}$ Financial support from CPB Netherlands Bureau for Economic Policy and the Dutch National Science Foundation (NWO-VENI 051.14.023 and NWO-VICI 453.03.606) is gratefully acknowledged. For valuable discussions and comments, we would like to thank Marcel Canoy, Robert Dur, Jan Potters, Arthur Schram, Jeroen van de Ven, Frans van Winden, participants a seminar at the University of Amsterdam, the Conference on "Incentives and Work Motivation in the Public Sector" 2005 at Erasmus University Rotterdam, and the 2006 EALE conference in Prague. The usual disclaimer applies.

${ }^{\dagger}$ Radboud University Nijmegen, Nijmegen School of Management, Thomas van Aquinostraat 5, 6525 GD Nijmegen, The Netherlands, j.vyrastekova@fm.ru.nl

${ }^{\ddagger}$ Corresponding author. University of Amsterdam, Amsterdam School of Economics, Roetersstraat 11, 1018 WB Amsterdam, The Netherlands, onderstal@uva.nl

${ }^{\S}$ CPB Netherlands Bureau for Economic Policy Analysis, P.O. Box 80510, 2508 GM The Hague, The Netherlands, pwck@cpb.nl 


\section{Introduction}

A reorganisation in a firm or the restructuring of the public sector often involves proposals to increase the power of employees' incentive schemes. Recent examples of such proposals in the public sector are with respect to teachers, employment offices, and medical practices (see Burgess and Ratto (2003) for a survey). Indeed, there is empirical evidence that high-powered incentive schemes positively affect workers' performance. ${ }^{1}$ Nalbantian and Schotter (1997) find similar results in the laboratory.

However, the literature also offers mechanisms which explain why low-powered incentive schemes may perform well. These include intrinsic motivation, positive reinforcement, mutual monitoring among team members, and opportunities for workers to reciprocate among each other within a team. ${ }^{2}$ In questionnaires, workers indicate that they highly appreciate non-pecuniary motivations like intrinsic incentives to perform the job (Frey and Jegen (2001)) as well as a fair relationship with the employer (Fehr and Schmidt (2004)). Indeed, Lavy (2002) (teachers), Knez and Simester (2001) (airlines), and Hamilton et al. (2003) (the garment industry) provide evidence on teams in which (low-powered) team incentives perform well. More generally, low-powered incentive schemes may outperform high-powered ones when the latter crowd out intrinsic motivation (Frey and Jegen (2001)).

\footnotetext{
${ }^{1}$ See, e.g., Drago (1991) and Lazear (2000). Gibbons (1997) and Prendergast (1999) provide overviews. Sunde (2009) and Franke (2011) observe similar effects in sports tournaments.

${ }^{2}$ See, e.g., Kandel and Lazear (1992), Gneezy and Rustichini (2000), Minkler (2004), Canton (2005), and Sliwka (2007).
} 
In this paper, we study the effect of increasing the power of employees' incentive schemes in a setting where workers self-selected into firms before being aware of the change in incentive scheme. Indeed, crowding-out of intrinsic motivation may be amplified when intrinsically motivated workers self-selected into firms with low-powered incentives (Delfgaauw and Dur (2008)). We, however, focus on how self-selection of workers into firms with varying power of the incentive schemes depends on trust and preferences for reciprocity, and how self-selection affects the performance of firms that increase the power of the incentive schemes.

We answer these questions using a laboratory experiment. This method is suitable because field data are likely to suffer from measurement and identification problems. Measurement problems may, for instance, arise in connection to workers' output. Even if output is measurable, the researcher has no information on an individual's effort and preferences. Identification problems may occur because it is not straightforward to isolate the effect of the power of the incentive scheme on a worker's performance from other effects. In contrast, in the laboratory we can observe each subject's effort and measure their preferences, and we can expose the same individual to different payment schemes and observe her reaction, while keeping the rest of the environment constant.

Subjects in our experiment had to choose between two payment schemes: a lowpowered one and a high-powered one. Subjects choosing the same scheme were matched together. For 10 rounds, subjects provided effort in a production game and they were 
paid according to the payment scheme of their choice. Next, all subjects played 10 more rounds in which they were paid according to the high-powered payment scheme. The parameters of the production game are such that only the low-powered incentive scheme is likely to trigger reciprocal behavior. Therefore, it may outperform the high-powered one if reciprocators are more likely to choose to work for a low-powered incentive scheme than money-maximisers. However, also money-maximisers who trust others to cooperate may choose the low-powered incentive scheme to free-ride. To analyse the role of trust and reciprocity, we let subjects submit strategies in the trust game and use these as measures for these characteristics.

Self-selection of employees in firms has received some attention in the empirical literature in the past few years. In his field experiment in a car glass company, Lazear (2000) not only observes that the average output per worker went up when the company increased the power of its workers' incentive scheme, he also finds that the firm was increasingly able to attract productive workers. Hamilton et al. (2003) on the other hand stress that collaboration skills in teams increase the output in a garment factory. They also observe that high-ability workers are more likely to join teams than low-ability workers.

Dohmen and Falk (2011), Cadsby et al. (2007), and Eriksson and Villeval (2008) observe sorting in the lab and find that more productive subjects are more likely to opt for high-powered payment schemes. In contrast to us, those authors do not examine the effect of increasing the power of the incentive scheme for those who choose the low- 
powered one. Keser and Montmarquette (2009) have a similar set-up as ours, with the differences that (1) they let each subject stay in the same two-player team for the duration of the experiment and (2) by construction, the maximum payoff is higher under team incentives than under individualistic incentives, while in our set-up it is the same. Keser and Montmarquette observe that team incentives are popular, and frequently lead to high output. In our experiment, subjects are randomly re-matched after each production game so that trigger strategies cannot explain the instances of cooperation we observe.

The remainder of the paper is organised as follows. In Section 2, we discuss the design of the experiment and our hypotheses. Section 3 includes the experimental observations. Section 4 concludes.

\section{The experiment}

In this section, we describe our experimental design and the hypotheses we wish to test.

\subsection{Design}

We ran 9 experimental sessions at Tilburg University. ${ }^{3}$ Subjects were paid for all points they earned in the experiment (on average 13 Euro including a 5 Euro participation fee for a session lasting approximately 1.5 hours). The experiments were fully computerised using z-Tree (Fischbacher (2007)). Of the 172 subjects, 134 participated in the main design, while 38 entered control sessions (see further below). In the main design, subjects

\footnotetext{
${ }^{3}$ Experiment instructions are available at http://www.sanderonderstal.com/Instructions/SelfselectionP2.doc.
} 
had to make decisions at four subsequent stages: ${ }^{4}$

1. the trust game;

2. a "labor market" in which subjects chose between team incentives (TEAM) and individual incentives (INDI);

3. the production game (10 rounds) in the chosen incentive scheme (TEAM or INDI);

4. the production game (10 rounds) in the imposed scheme INDI.

To measure subjects' reciprocity and trust (i.e. their belief in others' reciprocity), we let them submit strategies for both roles in the trust game (Berg et al. (1995)). In this game, a sender decides how much of her 10 point endowment to transfer to a receiver. The points sent are tripled and the receiver has to decide how many points to return to the sender. A subject's transfer in the role of sender [the average fraction she returns as receiver] measures her trust [reciprocity]. At the end of the session, the computer determined at random which role each subject played and to whom she was matched..$^{5,6}$

In the "labor market" stage, subjects chose a payment scheme for 10 rounds of the production game; either the individual payment scheme INDI, or the team payment scheme

\footnotetext{
${ }^{4}$ Subjects only received instructions for the stage that they were on, and were not informed about the stages to follow.

${ }^{5}$ Vyrastekova and Onderstal (2010) discuss this "behind the veil of ignorance" design and observe that subjects behave similarly as in the standard design. Moreover, Vyrastekova and Garikipati (2005) provide evidence that transfers are a reasonable measure of beliefs in positive reciprocity.

${ }^{6}$ Subjects learned the outcomes for the trust game only at the end of the experiment so that these would not affect behaviour in the rest of the experiment.
} 
TEAM. Subjects opting for the same scheme were randomly matched into teams of two in each round. ${ }^{7}$ In the production game, they provided input in two tasks. In Task 1, each subject independently chose effort $e \in\{L, H\}$. In Task 2, after observing the effort of the other subject, each subject chose a reward $r \in\{0, R\}$. Table 1 below includes the parameters of TEAM and INDI. We ran four sessions (with 78 subjects) in parametrisation P1 and three sessions (with 56 subjects) in parametrisation P2.

\begin{tabular}{|c|c|c|c|c|c|}
\hline \multicolumn{6}{|c|}{ Parametrisation P1 } \\
\hline \multicolumn{3}{|c|}{ INDI } & \multicolumn{3}{|c|}{ TEAM } \\
\hline Task 1 & $e=H$ & $e=L$ & Task 1 & $e=H$ & $e=L$ \\
\hline$e=H$ & 6,6 & 4,4 & $e=H$ & 6,6 & 0,8 \\
\hline$e=L$ & 4,4 & 2,2 & $e=L$ & 8,0 & 2,2 \\
\hline Task 2 & $r=R$ & $r=0$ & Task 2 & $r=R$ & $r=0$ \\
\hline$r=R$ & 8,8 & $-6,14$ & $r=R$ & 8,8 & $-2,10$ \\
\hline$r=0$ & $14,-6$ & 0,0 & $r=0$ & $10,-2$ & 0,0 \\
\hline \multicolumn{6}{|c|}{ Parametrisation P2 } \\
\hline \multicolumn{3}{|c|}{ INDI } & \multicolumn{3}{|c|}{ TEAM } \\
\hline Task 1 & $e=H$ & $e=L$ & Task 1 & $e=H$ & $e=L$ \\
\hline$e=H$ & 6,6 & 4,2 & $e=H$ & 6,6 & $-1,7$ \\
\hline \multirow[t]{2}{*}{$e=L$} & 2,4 & 0,0 & $e=L$ & $7,-1$ & 0,0 \\
\hline & & & \multicolumn{3}{|c|}{ 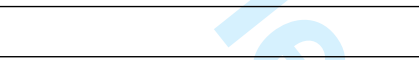 } \\
\hline Task 2 & $r=R$ & $r=0$ & Task 2 & $r=R$ & $r=0$ \\
\hline$r=R$ & 6,6 & $-6,12$ & $r=R$ & 6,6 & $-1,7$ \\
\hline$r=0$ & $12,-6$ & 0,0 & $r=0$ & $7,-1$ & 0,0 \\
\hline
\end{tabular}

Table 1: Experiment payoff matrices of the production games

\footnotetext{
${ }^{7}$ Subjects did not know how many others chose the same scheme. Therefore, they could not condition their behaviour on the self-selection procedure outcome. In each session, more than four subjects selfselected into each scheme so that we did not observe repeated interaction of a fixed matched pair.
} 
The production games have the following interpretation. Subjects form a two-person production team in a firm. " $e=H$ " [" $e=L "]$ refers to high [low] effort in producing own output and " $r=R$ " [" $r=0$ "] to [not] rewarding/helping the team mate. ${ }^{8}$ The payoffs are higher if both choose $e=H[r=R]$ than if both choose $e=L[r=0]$. The interpretation is that the firm shares the fruits of high output with the workers. In INDI, a worker is mainly rewarded for her own output. So, her payoffs are high if she chooses $e=H$ in Task 1 and if her team mate chooses $r=R$ in Task 2. In contrast, in TEAM, workers are to a large extent rewarded by team output, so relative to INDI, they have more incentives to opt for $e=L$ in Task 1 and fewer incentives to choose $r=0$ in Task $2 .^{9}$

After 10 rounds, we informed subjects that they would play 10 more rounds, and that they would be paid according to the INDI scheme. We again re-matched them after each round, but only among those who chose the same scheme in the labor market. ${ }^{10}$

\footnotetext{
${ }^{8}$ In the experiment, we used neutral labels: "PULL" instead of $e=H$, "PUSH" instead of $e=L$, "GIVE" instead of $r=R$, and "KEEP" instead of $r=0$.

${ }^{9}$ The parameters are consistent with the following production game. The costs of effort are $c\left(e_{i}\right)$, with $c(L)=0<c(H)<H-L$. Cost of reward are $k\left(r_{i}\right)$ where $k(0)=0$ and $0<k(R)<R$. An agent's effort raises her own output, while her reward raises the output of her team member (which could be interpreted as helping the other person or being cooperative with her). More precisely, the relationship between the efforts and the rewards of players $i$ and $j$ forming one team and the output $o_{i}$ of player $i$ is $o_{i}=e_{i}+r_{j},\{i, j\}=\{1,2\}$.

Player $i$ 's payment equals $p_{i}=\alpha o_{i}+(1-\alpha) o_{j},\{i, j\}=\{1,2\}$, where $\alpha$ is a measure of the extent to which an agent's own output determines her payment. In the extreme case where $\alpha=1$, only her own output determines what she gets, while the other extreme $\alpha=\frac{1}{2}$ indicates that the payments are only based on total team performance.

The parameters used for the parametrisation $\mathrm{P} 1(\mathrm{P} 2)$ are: $H=18(14), L=2(0), c(H)=12(8)$, $R=16(14), k(R)=8(8), \alpha_{I N D I}=\frac{7}{8}\left(\frac{6}{7}\right)$, and $\alpha_{T E A M}=\frac{5}{8}\left(\frac{1}{2}\right)$.

${ }^{10}$ Note that we used a cautious design in that subjects did not have the opportunity to sort themselves into teams endogenously or to build reputation. Free-rider problems could be alleviate if the subjects are able to form groups endogenously on the basis of historical information or repeated interaction. These options remain open for future research. Keser and Montmarquette (2009) is a promising first step.
} 
To evaluate how self-selection affects our results, we ran control sessions where we forced all subjects to start with TEAM. We did so with 18 and 20 subjects in P1 and P2 respectively. Subjects submitted the trust game strategies, and then played 10 rounds of TEAM. After that, we informed subjects that they would participate in 10 more rounds and we exposed them to the TEAM scheme in the other parametrisation. ${ }^{11}$

\subsection{Hypotheses}

Consider the payoffs in Table 1. First, note that for money maximising subjects, the two-stage games have a unique subgame perfect Nash equilibrium (SPNE). In the SPNE of INDI [TEAM], both team members choose $e=H[e=L]$ in Task 1 and $r=0$ in Task 2. It is readily verified that in the SPNE, a subject's payoff is higher in INDI than in TEAM. Therefore, a money maximising subject will always choose INDI. Moreover, the power of incentives in INDI is higher than in TEAM. The reason is that in Task 1 of INDI, $e=H$ is the SPNE strategy, in contrast to TEAM, while both choose the same action in Task 2 .

However, TEAM may yield a better outcome than INDI if the population contains sufficiently many reciprocal subjects, i.e. subjects who wish to cooperate as long as their team mate does so as well. A reciprocator may play the following "tit-for-tat" strategy

\footnotetext{
${ }^{11}$ We chose this approach so as to let subjects earn approximately the same amount of income as in the other sessions. In our analysis, we only compare data on the TEAM payment scheme without self-selection in rounds 1 to 10 to data on TEAM payment scheme with self-selection (rounds 1 to 10 as well).
} 
in TEAM: She starts off by choosing $e=H$ in Task 1 , and she continues to cooperate by choosing $r=R$ in Task 2 if and only if the other team member chooses $e=H$ in Task 1 as well. Note that in TEAM, a money maximising (i.e., non-reciprocal) subject may "free-ride" on a reciprocal subject by choosing $e=H$ in Task 1 and $r=0$ in Task 2 . Observe that a money maximiser obtains a higher payoff in TEAM than in INDI if she meets a reciprocator who plays the above "tit-for-tat" strategy.

So, the most important determinant for subjects to choose TEAM seems to be their level of trust. Those who trust the other subject to reciprocate have an incentive to enter TEAM. Others prefer INDI.

Hypothesis 1a: Labor market. Subjects with a high trust level are more likely to choose TEAM than those with a low one.

Hypothesis 1b: Actions. Subjects who choose INDI play $e=H$ in Task 1 and $r=0$ in Task 2. Reciprocal subjects who choose TEAM play $e=H$ in Task 1 and, if the other does so as well, chooses $r=R$ in Task 2 and $r=0$ otherwise. Non-reciprocal subjects who choose TEAM play $e=H$ in Task 1 and $r=0$ in Task 2 .

Next, we spell out the hypothesis most relevant for policy: Does a team perform better the higher the power of the incentive scheme? If we assume an increasing relationship between the subjects' payoffs and the profits of the firm, the answer is no. The reason is that subjects will only choose a scheme if they expect the payments under this scheme to 
be higher than under the other scheme.

Hypothesis 2: The power of incentives. Subjects who choose to play TEAM in rounds 1-10 produce more in rounds 1-10 than in rounds $11-20$ (in which they play INDI).

We may find support for Hypothesis 2 if reciprocal subjects self-select in TEAM. Indeed, if sufficiently many subjects choose $e=H$ in Task 1 and $r=R$ in Task 2, they perform better in TEAM than in INDI.

Finally, we address the question to which extent self-selection contributes to TEAM outperforming INDI - if it does. Subjects may select TEAM to express their willingness to provide high effort without explicit monetary incentives. It is especially relevant when we think of firms operating under team-based incentives. The incentive scheme is usually known to the workers entering the firm beforehand, i.e., it is one of the factors upon which they select the firm. If self-selection matters then it generates a reason for the firm to stick to TEAM incentives. We can evaluate the role of self-selection for the success of team-based incentives by comparing the behaviour of subjects in TEAM who self-selected this scheme, to subjects who were forced to play TEAM. If more cooperation is found in the former group, then self-selection is responsible for at least part of the success of TEAM.

Hypothesis 3: Self-selection. Subjects who select TEAM in the main design (in which they can choose between TEAM and INDI) are more likely to choose $e=H$ in Task 
1 and $r=R$ in Task 2 than those who participate in the control design (in which all play TEAM).

Hypothesis 3 will not be rejected if the initial sorting of subjects into TEAM and INDI results in higher payoffs for subjects in TEAM. The driving force may be that those who choose TEAM trust more and are more reciprocal than those choosing INDI. If all subjects are forced to play TEAM, less reciprocity may be realised, so that the output in TEAM ends up being lower than it would be under sorting. Note that all hypotheses will be rejected if the population only contains money maximising subjects.

\section{Data analysis}

In this section, we address the results from our experiment in the light of the three hypotheses formulated above.

\subsection{Labour market and actions}

A substantial fraction of subjects chooses TEAM in both parametrisations: $34 \%$ in $\mathrm{P} 1$ and $44 \%$ in P2. This finding allows us to reject the hypothesis that all select INDI, which is the optimal choice if all play according to the SPNE. In support of Hypothesis 1a, we find that subjects selecting TEAM trust more and are more reciprocal. Subjects selecting TEAM trust others significantly more than those selecting INDI (5.5 versus 4.6 points; Mann-Whitney $\mathrm{U}$ test, $p=0.049$ ). On average, subjects selecting TEAM return a fraction 
that leaves senders' investment profitable (i.e. more than one third of the received number of points), unlike subjects selecting INDI.

Table 2 includes Probit estimates for the choice of TEAM. The outcomes show that there is a non-linear relationship between trust and reciprocity on one hand, and the choice of the payment scheme on the other. Both trust and reciprocity have a positive effect on the choice of TEAM (in line with the above non-parametric tests). However, the interaction term is negative and (weakly) significant. Its parameter estimate implies that given values of reciprocity below 0.57 , higher trust makes entry into TEAM more likely.

\begin{tabular}{lcc}
\hline \hline Variable & Coefficient estimate & Standard error \\
\hline Trust & $0.057^{* *}$ & $(0.024)$ \\
Reciprocity & $0.74^{* *}$ & $(0.33)$ \\
Trust * reciprocity & $-0.10^{*}$ & $(0.052)$ \\
P2-dummy & -0.059 & $(0.089)$ \\
\hline Number of observations & 134 & \\
Log likelihood & -85.44 & \\
\hline$*[* *]$ indicates significance at the $10 \%[5 \%]$ level. & \\
\hline \hline
\end{tabular}

Table 2: Probit estimates of choice of TEAM. The coefficients are expressed as marginal effects.

These observations have two implications. First, subjects who exhibit high trust are likely to enter TEAM, in line with Hypothesis 1a. Second, TEAM may attract "freeriders", i.e., people who believe that sufficiently many others are reciprocators without having the attention to reciprocate themselves. In other words, these subjects may imitate behaviour of reciprocators in Task 1, but free-ride on them in Task 2. Consequently, the TEAM scheme attracts reciprocal as well as money maximising subjects, as long as their 
trust is sufficiently high. ${ }^{12}$

Observation 1a (Labor market): A non-negligible fraction of subjects (more than one third in both parametrisations) selects TEAM. On average, subjects who do so trust more and are more reciprocal than subjects who opt for INDI. However, moneymaximisers (subjects with low reciprocity levels) also enter TEAM if their trust-level is sufficiently high.

We now turn to analysing subjects' strategies under the payment scheme of their choice. From Figure 1, we derive that in Task 1, subjects in INDI choose nearly exclusively $e=H$, consistent with our equilibrium prediction. Also in TEAM, we observe $e=H$ : in $\mathrm{P} 1[\mathrm{P} 2]$ on average $31 \%[69 \%]$ of subjects choose $e=H$. We predicted that reciprocators, trusting in reciprocity of others, will enter TEAM and choose $e=H$ in part 1 with probability 1. The presence of $e=L$ choices in TEAM can be explained by the fact that money-maximisers expect to gain 8 [7] points in part 1 of TEAM if matched to reciprocators, but only 6 points in part 1 in INDI in P1 [P2]. Therefore, free-riding money-maximisers with trust in reciprocity have incentives to enter TEAM, and choose $e=L$, and such incentives are higher in P1, implying a higher fraction of $e=L$ choices than in P2. This is indeed the pattern that we find.

\footnotetext{
${ }^{12}$ We tested for the possibility of multi-collinearity between trust and reciprocity, and found this not to be of importance. We also estimated the model with a gender dummy as an additional control, but this variable was insignificant and did not change our trust and reciprocity coefficient values substantially.
} 


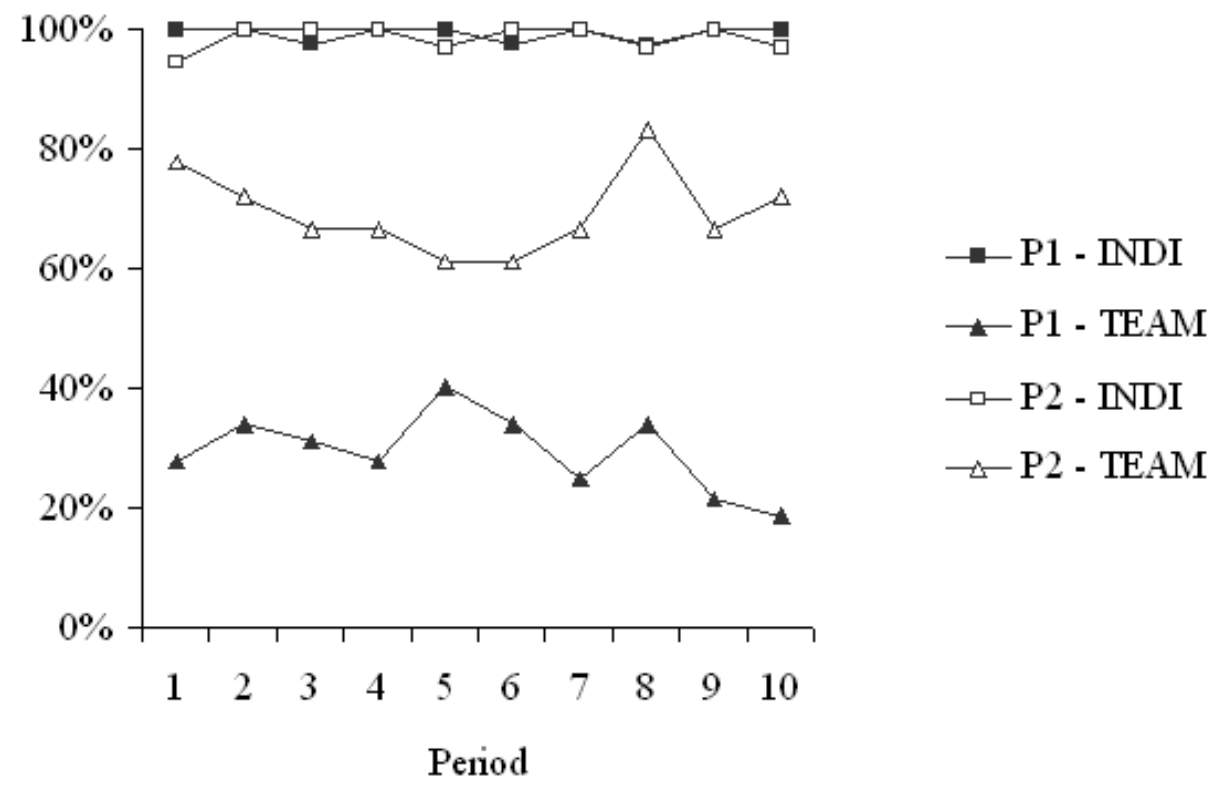

Figure 1: Action $e=H$ in Task 1 for $\mathrm{P} 1$ and $\mathrm{P} 2$.

Figure 2 indicates that high effort in Task $2(r=R)$ is much more likely in TEAM than in INDI, especially when both subjects chose high effort in Task $1(e=H)$. We use a conditional Logit model to investigate whether subjects employ the above "tit-fortat strategy" in Task 2 (see Table 3 for the estimates). This specification accounts for subject-specific effects because a subject's choices in Tasks 1 and 2 may depend on her individual characteristics. For both $\mathrm{P} 1$ and P2, it is apparent that the probability of choosing $r=R$ is highest when both players chose $e=H$ in Task 1 (the coefficients on any other history observed are significant and negative). Moreover, we observe that those 
who choose $r=R$ in TEAM are more likely to be reciprocators than those who choose $r=0$. In the trust game, the former return on average $51 \%[39 \%]$ of the sent amount in $\mathrm{P} 1$ [P2], while the latter return on average 39\% [25\%]. The difference is significant in both cases (Mann-Whitney U test, $p=0.090[p=0.008])$. So, reciprocators are less inclined to "free ride" in Task 2.

(i) Parametrization P1

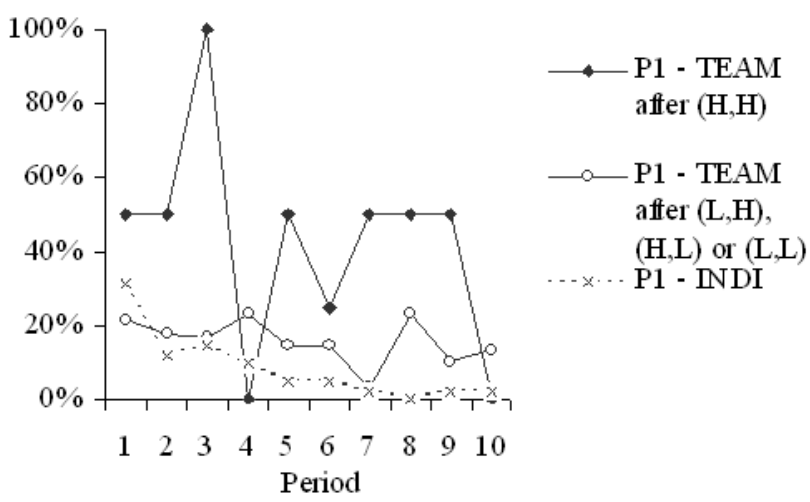

(ii) Parametrization P2

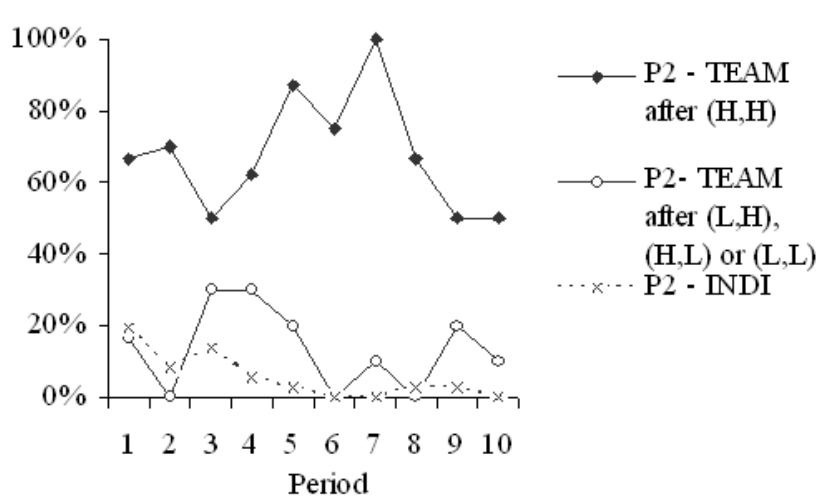

Figure 2: Fraction of subjects choosing action $r=R$ in Task 2 in P1 and P2.

The conditional Logit results in Table 3 also show evidence on the dynamics that may evolve during the production games. In our experiments, subjects are re-matched anonymously into new pairs after each round of the production game. So within this setting any dynamic effects constitute general learning or demotivation effects that are not specific to combinations of playing partners. Of course, participants may respond to their experiences in earlier rounds. One way to model such effects is to include past individual reciprocity outcomes in the decision model. However, using lagged (autoregressive) 
variables in conditional Logit (fixed effects) models yields inconsistent outcomes of our parameters of interest (lagged effects and fixed effects then cannot be disentangled). As an alternative, we can however include a general, baseline time trend for the number of rounds that has been played to account for dynamic effects. For both parameterisations we then find a negative, but insignificant coefficient value for rounds 6-10 (as compared to $1-5)$.

\begin{tabular}{|c|c|c|c|}
\hline \multicolumn{2}{|c|}{ Task 1 action } & \multicolumn{2}{|c|}{ Parametrisation } \\
\hline Player & Co-player & $\mathrm{P} 1$ & $\mathrm{P} 2$ \\
\hline$e=H$ & $e=H$ & \multicolumn{2}{|c|}{ reference group } \\
\hline$e=H$ & $e=L$ & $-1.50(0.636)^{* *}$ & $-3.36(0.867)^{* * *}$ \\
\hline$e=L$ & $e=H$ & $-1.53(0.681)^{* *}$ & $-3.25(0.908)^{* * *}$ \\
\hline$e=L$ & $e=L$ & $-1.81(0.608)^{* * *}$ & $-2.19(0.966)^{* *}$ \\
\hline \multicolumn{2}{|c|}{ Dummy rounds 6-10 } & $-0.101(0.082)$ & $-0.109(0.095)$ \\
\hline \multicolumn{2}{|c|}{ Number of observations } & 190 & 120 \\
\hline \multicolumn{2}{|c|}{ Dropped (no variation) } & 150 & 70 \\
\hline \multicolumn{2}{|c|}{ Log likelihood } & -69.457 & -31.571 \\
\hline
\end{tabular}

Table 3: Conditional Logit model estimates for the probability of $r=R$ in Stage 2 (standard errors between brackets).

Observation 1b (Actions): In INDI, in the far majority of cases, subjects choose $e=H$ and $r=0$, which is the SPNE. In TEAM, many subjects deviate from the SPNE by choosing $e=H$ or $r=R$. Those who select TEAM are more likely to choose $r=R$ in Task 2 if they observe history $(e=H, e=H)$ in Task 1 than another history. In TEAM, a subject is more likely to opt for $r=R$ the more reciprocal she is. 


\subsection{The power of incentives}

Is it profitable for the firm to increase the power of the incentive scheme? Subjects' average profits per round in $\mathrm{P} 1[\mathrm{P} 2]$ are lower [higher] in the self-selected TEAM scheme than in the imposed INDI scheme; see Table 4. Moreover, in both parametrisations, individuals who self-select into TEAM earn significantly more than the payoff predicted by the Nash equilibrium for this scheme. These observations suggest that the firm can increase output by switching from TEAM to INDI in P1, but not in P2.

\begin{tabular}{cccccc}
\hline \hline & \multicolumn{2}{c}{ Payoff in SPNE } & \multicolumn{2}{c}{ Average payoff } & Mann-Whitney U test \\
Parametrisation & INDI & TEAM & INDI & TEAM & INDI = TEAM \\
\hline P1 & 6 & 2 & $6.6(0.2)$ & $4.6(0.28)$ & $\mathrm{p}=0.000$ \\
P2 & 6 & 0 & $6.3(0.16)$ & $6.6(0.39)$ & $\mathrm{p}=0.002$ \\
\hline \hline
\end{tabular}

Table 4: Average and Nash equilibrium payoffs per subject per round in the self-selected scheme (rounds 1 to 10) and Mann-Whitney U test (standard errors between brackets).

When INDI is imposed on all subjects (in rounds 11 to 20), disregarding their choice of the scheme in the labor market stage, individual behaviour is found to correspond closely to the SPNE predictions, with nearly $95 \%$ of equilibrium actions. Table 5 presents the average payoffs for subjects who chose TEAM in periods 1 to 10 (in which they play TEAM) and periods 11 to 20 (in which they play INDI). The economic performance of the subjects who chose TEAM significantly changes when they are forced to play INDI. However, the change is not unidirectional. In P1, we observe a significant increase in output. The opposite is found in P2: Performance is worse in INDI than in TEAM. 
Therefore, increasing the power of the incentive scheme is not profitable in P2. Note that these observations cannot be related to the subject pool composition, because subjects are matched in the same subset of the pool as when they play according to the self-selected scheme.

\begin{tabular}{cccccc}
\hline \hline & \multicolumn{2}{c}{ Payoff in SPNE } & \multicolumn{2}{c}{ Avg. payoff of those choosing TEAM } & Wilcoxon signed rank test \\
Parametrisation & INDI & TEAM & TEAM (rounds 1-10) & INDI (rounds 11-20) & INDI = TEAM \\
\hline P1 & 6 & 2 & $4.6(0.28)$ & $6.1(0.11)$ & $\mathrm{p}=0.001$ \\
P2 & 6 & 0 & $6.6(0.39)$ & $6.1(0.18)$ & $\mathrm{p}=0.044$ \\
\hline \hline
\end{tabular}

Table 5: Average and Nash equilibrium payoffs for 10 rounds in the forced payment scheme TEAM only for subjects who previously self-selected into INDI.

Observation 2 (The power of incentives): Subjects who choose TEAM, when exposed to INDI, improve performance in $\mathrm{P} 1$, but not in $\mathrm{P} 2$, in which performance is worse.

The explanation of this observation is based on the fact that cooperation is more attractive in $\mathrm{P} 2$ than in $\mathrm{P} 1$. In $\mathrm{P} 2$, subjects lose more points $(6-0=6)$ when they fail to initiate cooperation than in $\mathrm{P} 1$ (where they lose $6-2=4$ points). At the same time, the incentives to free-ride on a cooperator are higher in P1 than in P2 (2 points vs. 1 point). As a result, we expect subjects to be less successful in sustaining cooperation in P1 than in P2. Therefore, in the case of strong (unobservable) interdependency between workers and strong incentives to cooperate under team incentives, switching from team incentives to individual incentives does not improve performance. 


\subsection{Self-selection}

We have observed that in P2, subjects who self-select in TEAM perform worse once they are forced into compensation scheme INDI. Is the success of TEAM explained by the fact that reciprocal subjects choose TEAM in the labor market? We address this question by comparing the actions in the production game in Task 1 and Task 2 with the control group in which subjects did not have a choice and were forced to compensation scheme TEAM. We find that in P1, self-selection has no effect ( $p=0.909$ Mann-Whitney $\mathrm{U}$ test). However, in P2, subjects earn significantly more in sessions in which they sort themselves into TEAM than when we force them to do so ( $p=0.016$ Mann-Whitney U test). More specifically, those who self-select are significantly more likely to choose $e=H$ in Task 1 (Mann-Whitney $\mathrm{U}$ test, $p=0.012$ ), and $r=R$ in Task 2 (Mann-Whitney $\mathrm{U}$ test, $p=0.005)$

Observation 3 (Self-selection): The impact of self-selection on subjects' behaviour in TEAM is small in P1. In contrast, in P2, subjects who are forced to play TEAM perform worse than those who select TEAM in the main design.

In P2, the performance in the scheme TEAM is better when subjects can self-select into this scheme than when they are assigned to it. In other words, self-selection partly explains why an increase in the power of the incentive scheme may have counterproductive effects. 


\section{Conclusion}

High-powered incentives stand high on the list of policy instruments that should improve the performance of organisations. Using a laboratory experiment, we examine (1) whether subjects' trust and reciprocity affects their self-selection in low- and high-powered incentive schemes and (2) whether teams perform better if the power of incentives is increased in situations where subjects can self-select. We observed that the more a subject trusts or the more reciprocal she is, the more likely she is to opt for low-powered incentives. Production decreases when subjects choosing low-powered incentives are confronted with high-powered incentives if the gains from cooperation are high, from the perspective of both the individual and the team. Self-selection partly explains this finding.

Our observations suggest that firms traditionally relying on reciprocal relationships of co-workers in teams should be cautious about increasing the power of the workers' incentive schemes, at least in the short run. ${ }^{13}$ For example, one may think of case managers at employment services, who often have to rely on their mutual expertise to find suitable jobs for their clients. Similar interdependencies may exist between medical doctors and between police officers. Another policy option is to strengthen the advantages of team pay, i.e., develop sorting mechanisms to attract reciprocal workers, or strengthen signalling mechanisms within the organisation.

\footnotetext{
${ }^{13}$ In the long run, employees who prefer low powered incentives may leave the firm and find jobs that better suit their preferences (see, e.g., Delfgaauw (2007)).
} 


\section{References}

Berg J., J. Dickhaut, and K. McCabe (1995) Trust, Reciprocity, and Social History, Games and Economic Behavior, 10, 122-142..

Burgess, S., and M. Ratto (2003) The Role of Incentives in the Public Sector: Issues and Evidence, Oxford Review of Economic Policy, 19, 285-300.

Cadsby, C.B., F. Song, and F. Tapon (2007) Sorting and Incentive Effects of Pay for Performance: An Experimental Investigation. Academy of Management Journal, 50, $387-405$.

Canton, E. (2005) Power of Incentives in Public Organizations When Employees Are Intrinsically Motivated, Journal of Institutional and Theoretical Economics, 4, 664-680.

Delfgaauw, J. (2007) Where to Go? Workers' Reasons to Quit and Intra- vs. Interindustry Job Mobility, Applied Economics, 39, 2057-2067.

Delfgaauw, J., and R. Dur (2008) Incentives and Workers' Motivation in the Public Sector, Economic Journal, 118, 171-191.

Dohmen, T., and A. Falk (2011) Performance Pay and Multi-dimensional Sorting: Productivity, Preferences and Gender, American Economic Review, 101, 556-590.

Drago, R. (1991). Incentives, Pay, and Performance: A Study of Australian Employees, Applied Economics, 23,1433-1446.

Eriksson, T. and M.C. Villeval (2008) Performance Pay, Sorting and Social Motivation, Journal of Economic Behavior and Organization, 68: 412-421. 
Fehr, E., and Schmidt, K.M. (2004) Fairness and Incentives in a Multi-task Principalagent Model, Scandinavian Journal of Economics, 106, 453-474.

Fischbacher, U. (2007) z-Tree. Zurich Toolbox for Readymade Economic Experiments, Experimental Economics, 10, 171-178.

Franke, J. (2011) The Incentive Effects of Levelling the Playing Field: An Empirical Analysis of Amateur Golf Tournaments, Applied Economics, forthcoming.

Frey, B., and Jegen, R. (2001) Motivation Crowding Theory: A Survey of Empirical Evidence, Journal of Economic Surveys, 15, 589-611.

Gibbons, R. (1997). Incentives and Careers in Organizations. In D.M. Kreps and K.F. Wallis (eds.), Advances in Economics and Econometrics: Theory and Applications (Seventh World Congress Volume 2). Cambridge: Cambridge University Press.

Gneezy, U., and Rustichini, A. (2000) Pay Enough or Don't Pay at All, Quarterly Journal of Economics, 115, 791-810.

Hamilton, B., J. Nickerson, and H. Owan (2003) Team Incentives and Worker Heterogeneity: An Empirical Analysis of the Impact of Teams on Productivity and Participation, Journal of Political Economy, 111, 465-497.

Kandel, E., and Lazear, E.P. (1992) Peer Pressure and Partnerships, Journal of Political Economy, 100, 801-817.

Keser, C., and Montmarquette, C. (2009) Voluntary versus Enforced Team Effort, working paper, Georg-August-Universität Göttingen. 
Knez, M., and Simester, D. (2001) Firm-wide Incentives and Mutual Monitoring at Continental Airlines, Journal of Labor Economics, 19, 743-772.

Lavy, V. (2002) Evaluating the Effect of Teachers' Group Performance Incentives on Pupil Achievement, Journal of Political Economy, 110, 1286-1317.

Lazear, E.P. (2000) Performance Pay and Productivity, American Economic Review, 90, 1346-1361.

Minkler, L. (2004) Shirking and Motivations in Firms: Survey Evidence on Worker Attitudes, International Journal of Industrial Organization, 22, 863-884.

Nalbantian, H.R., and Schotter, A. (1997) Productivity under Team Incentives: An Experimental Study, American Economic Review, 87, 314-341.

Prendergast, C. (1999) The Provision of Incentives in Firms. Journal of Economic Literature, 37, 7-63

Sliwka, D. (2007), Trust as a Signal of a Social Norm and the Hidden Costs of Incentive Schemes, American Economic Review, 97, 999-1012.

Sunde, U. (2009), Heterogeneity and Performance in Tournaments: A Test for Incentive Effect Using Professional Tennis Data, Applied Economics, 41, 3199-3208.

Vyrastekova, J., and Garikipati, S. (2005) Beliefs and Trust: An Experiment, CentER Discussion Paper, Tilburg University.

Vyrastekova, J., and Onderstal, S. (2010) The Trust Game Behind the Veil of Ignorance: A Note on Gender Differences, Tinbergen Institute Discussion Paper. 